\title{
BOOST and Readmissions: Thinking Beyond the Walls of the Hospital
}

\author{
Ashish K. Jha, MD, MPH*
}

Department of Health Policy and Management, Harvard School of Public Health, Boston, Massachusetts.

Although hospital readmissions have been a problem for at least the past 5 decades, they are now receiving more attention than ever before. Starting with the 2007 Medicare Payment Advisory Commission report detailing the vast scope of the problem, ${ }^{1}$ readmissions have garnered substantial policy interest, culminating with Congress' inclusion of a penalty for hospitals with "excessive" readmission rates in the Affordable Care Act. Clinical leaders have become increasingly active in this issue as well, and hospitals around the nation have become engaged in finding ways to reduce the number of times patients return after discharge.

The Hospital Readmissions Reduction Program (HRRP), which is the penalty program put in place by Congress to address readmissions, has been controversial from its inception. Supporters point to the large number of patients whose discharge is fraught with poor communication, ineffective medication management, and inadequate handoffs to the primary care physician. Critics have countered that only a small proportion of readmissions are likely preventable by what hospitals can control, ${ }^{2}$ and that patient factors, especially social and economic circumstances, ${ }^{3}$ primarily drive readmissions. Despite this debate, we can all agree there is ample opportunity to improve the care of patients at the time of discharge.

In this context, we see important evidence emerging from the Better Outcomes by Optimizing Safe Transitions (BOOST) program. Funded by the Hartford Foundation among others, BOOST is specifically aimed at improving care transitions among older hospitalized adults. BOOST focuses on identifying those at highest risk for readmissions, communicating the discharge plan effectively, and ensuring close followup, both through phone calls after discharge and timely appointments with primary care providers. These are all interventions that seem intuitively like good ideas. In this issue of the Journal of Hospital Medicine, leaders of the BOOST program report on the impact on readmissions rate. ${ }^{4}$ However, as the accompanying editorial points out, the data are disap-

*Address for correspondence and reprint requests: Ashish Jha, MD, Department of Health Policy and Management, Harvard School of Public Health, 677 Huntington Avenue, Boston, MA 02115; Telephone: 617-4325552; Fax: 617-432-4494; E-mail: ajha@hsph.harvard.edu

Received: June 5, 2013; Accepted: June 6, 2013 2013 Society of Hospital Medicine DOI 10.1002/jhm.2069

Published online in Wiley Online Library (Wileyonlinelibrary.com). pointing. ${ }^{5}$ The evidence, seen in the best possible light, suggests a small improvement among a very select group of hospitals. Although the authors should be commended for writing up their findings, the fact that 19 of the 30 hospitals that received substantial training and assistance through the BOOST program chose not to report their data is unconscionable. The decision by those 19 hospitals to withhold data makes the results nearly uninterpretable and jeopardizes the hard work that so many others have engaged in. BOOST should require that hospitals agree to share data as a condition of participation in the program.

The Hansen study, ${ }^{4}$ despite its disappointing findings, may signal that it is time for a new approach. First of all, we may need to focus on different metrics. Looking ahead, the most important question may not be "Does BOOST lower readmission rates?" but rather "Does BOOST improve the care for patients at the time of discharge from the hospital?" There are several good measures of the quality of a care transition, such as those by Coleman and colleagues, ${ }^{6}$ and these could be used to measure the quality of care hospitals deliver at discharge. We could also develop new metrics of transitions of care. For example, hospitals truly committed to improvement could field an ongoing survey of primary care physicians in their community to ensure that care transitions are happening smoothly from the primary care providers' perspective. Patient experience metrics, beyond those captured in the Hospital Consumer Assessment of Healthcare Providers and Systems survey, may be necessary to better assess patient and family perspectives on the transition from the hospital to home. These and other approaches can help hospitals better understand how effectively they manage the handoff as patients leave their doors.

However, we should also recognize that although such approaches may improve care transitions, they are unlikely to substantially reduce readmissions. Instead, hospitals serious about reducing readmissions may need to reconsider their business model. ${ }^{7}$ In the days following a discharge, patients are medically and socially vulnerable. Patients without robust social support at home may need more than just the right medications, a phone call, or a follow-up appointment. They may need help with groceries, having their meals prepared, or getting a ride to the doctor's office. Hospitals that want to reduce readmissions may need to make investments in creating the community and social support that so many patients lack when they 
leave the hospital. This has never been part of the hospital business model before, but it may be time for a change.

The HRRP, an effort by federal policymakers to drive down readmissions through penalties, has clearly begun to make hospitals think about changing their business models in precisely these ways. Readmission rates are falling, although a concurrent increase in the number of patients being admitted to "observation status" makes it unclear whether patient care has actually improved. More data and time will tell. Furthermore, the program as currently designed targets hospitals that care for the sickest and poorest patients for penalties. ${ }^{8}$ There are plenty of good options for addressing these unintended consequences, such as comparing safety-net hospitals' performance to other similar institutions, or focusing only on preventable readmissions. However, regardless of its limitations, the HRRP in some form or another is here to stay. Therefore, hospitals will need to find ways to reduce readmissions, and programs like BOOST, even when executed perfectly, will be necessary but likely insuffi- cient. Improving the quality of care transitions is critically important. But to truly get to better outcomes for older Americans, hospitals will need to think beyond their 4 walls.

\section{References}

1. Report to the Congress: Promoting Greater Efficiency in Medicare. Washington, DC: Medicare Payment Advisory Commission; 2007.

2. van Walraven C, Bennett C, Jennings A, Austin PC, Forster AJ. Proportion of hospital readmissions deemed avoidable: a systematic review. CMAJ. 2011;183(7):E391-E402.

3. Joynt KE, Orav EJ, Jha AK. Thirty-day readmission rates for Medicare beneficiaries by race and site of care. JAMA. 2011;305(7):675-681.

4. Hansen LO, Greenwald JL, Budnitz T, Howell E, Halasyamani L, Maynard G, Vidyarthi A, Coleman EA, Williams MV. Project BOOST: Effectiveness of a Multihospital Effort to Reduce Rehospitalization. J Hosp Med. 2013;8(8):421-427.

5. Auerbach A, Fang M, Glasheen J, Brotman D, O’Leary KJ, Horwitz LI. BOOST: Evidence Needing a Lift. J Hosp Med. 2013;8(8):468469.

6. Coleman EA. The Care Transitions Program Web site. Available at: http://www.caretransitions.org/ctm_main.asp. Accessed June 6, 2013.

7. Joynt KE, Jha AK. A path forward on Medicare readmissions. N Engl J Med. 2013;368(13):1175-1177.

8. Joynt KE, Jha AK. Characteristics of hospitals receiving penalties under the Hospital Readmissions Reduction Program. JAMA. 2013; 309(4):342-343. 